\title{
Currículo contextualizado em escolas do campo: relatos de uma experiência
}

\author{
SANTOS, Rayane Pereira ${ }^{1}$ \\ RODRIGUES, Ana Cláudia da Silva²
}

\section{RESUMO}

Este trabalho apresenta um recorte de uma discussão sobre contextualização a partir da pesquisa intitulada: "Currículo contextualizado: trilhando caminhos para a valorização da identidade campesina", cujo objetivo foi analisar como o processo de contextualização curricular contribui para a valorização da realidade do campo. A abordagem metodológica utilizada foi qualitativa do tipo estudo de caso; como instrumento de coleta de dados, utilizou-se a entrevista semiestruturada realizada com nove profissionais da educação do campo de uma instituição escolar da zona rural, localizada no município de Bananeiras/PB. Os dados foram analisados por meio da Análise de Conteúdo de Bardin (2011); foram organizadas quatro categorias: currículo, contextualização, identidade e educação do campo. Apresenta-se aqui a categoria Contextualização, enfatizando como o contexto campesino pode contribuir para que o ensino seja significativo. Constatou-se que a contextualização reforça a valorização da identidade campesina, da escola e do local em que a mesma está inserida.

Contextualização. Currículo. Educação do Campo.

\section{Contextualized curriculum in country schools: reports of an experience}

\section{ABSTRACT}

This paper presents a clipping of a discussion about contextualization from the research entitled: "Contextualized Curriculum: Walking Paths for the Appreciation of Peasant Identity", whose objective was to analyze how the process of curricular contextualization contributes to the appreciation of the reality of the field. The methodological approach used was a qualitative case study, as a data collection instrument was used the semi-structured interview conducted with nine field education professionals from a rural school institution

\footnotetext{
${ }^{1}$ Especialista em Desenvolvimento Humano e Educação Escolar pela Universidade Estadual da Paraíba. Graduada em Pedagogia pela Universidade Federal da Paraíba. E-mail: rayane.leif@gmail.com. Lattes: http://lattes.cnpq.br/3592136711789723. ORCID: https://orcid.org//0000-0003-2835-6722.

2 Doutora em Educação pela Universidade Federal da Paraíba. Professora do DFE/CE/UFPB, credenciada no Programa de Pós-graduação em Educação da Universidade Federal da Paraíba e Líder do grupo de pesquisa Currículo e Práticas Educativas. E-mail: anaclaudia@ce.ufpb.br. Lattes: http://lattes.cnpq.br/6240637144545401. ORCID: https://orcid.org/0000-0001-6621-1861.
}

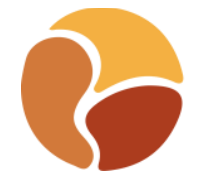

Interritórios | Revista de Educação Universidade Federal de Pernambuco, Caruaru, BRASIL | V.5 N.9 [2019] 
located in Bananeiras/PB. Data were analyzed using Bardin's Content Analysis (2011), four categories were organized: curriculum, contextualization, identity and field education. The category Contextualization is presented here, emphasizing how the peasant context can contribute to meaningful teaching. It was found that the contextualization reinforces the appreciation of the peasant identity, the school and the place where it is inserted.

Contextualization. Curriculum. Field Education.

\section{Curriculum contestualizzato ne le scuole de le aree rurali: il raconto di un vissuto}

\section{RIASSUNTO}

Questo lavoro espone una discussione sulla contestualizzazione basata sulla ricerca dal titolo: "Curriculum contestualizzato: la via per la valorizzazione dell'identità rurale", il cui obiettivo é analizzare come il processo ha contribuito ne la valutazione del le persone che vivono ne le aree rurali. Un approccio metodologico utilizzato per il tipo qualitativo di studio, come strumento per la raccolta di dati utilizzati in un'intervista semi-strutturata condotta con il nove maestri di un istituto scolastico dell'area rurale nella cittá di Bananeiras/PB. Per le analisi é stata scelta na teoria de Bardin (2011) o datto sono stati organizzati in quattro categorie: curriculum, contestualizzazione, identità e educazione rurale. È presentato qui nella categoria Contextualização, sottolineando come o il contesto contadino può contribuire in modo che non sia significativo. La conclusione fa pensare che contextualizare contribuisce per la valorizzazione dell'identità contadina.

Contestualizzazione. Curriculum. Educazione Rurale.

\section{Plan de estudios contextualizado en escuelas rurales: informes de una experiencia}

\section{RESUMEN}

Este artículo presenta un recorte de una discusión sobre la contextualización de la investigación titulada: "Currículum contextualizado: senderos para la apreciación de la identidad campesina", cuyo objetivo era analizar cómo el proceso de contextualización curricular contribuye a la apreciación de la realidad del campo. El enfoque metodológico utilizado fue un estudio de caso cualitativo; Como instrumento de recolección de datos, utilizamos una entrevista semiestructurada con nueve profesionales de educación rural de una institución escolar rural, ubicada en el municipio de Bananeiras / PB. Los datos se analizaron utilizando Bardin Content Analysis (2011); Se organizaron cuatro categorías: currículum, contextualización, identidad y educación sobre el terreno. La categoría Contextualización se presenta aquí, enfatizando cómo el 
contexto campesino puede contribuir a una enseñanza significativa. Se encontró que la contextualización refuerza la apreciación de la identidad campesina, la escuela y el lugar donde se inserta.

Contextualización. Plan de estúdios. Educación de campo.

\section{INTRODUÇÃO}

Em tempos de tentativas de homogeneização dos sujeitos e do ensino, a partir de políticas como a Base Nacional Comum Curricular, faz-se importante apresentar os resultados de experiências em contextualização do currículo para suscitar o debate sobre a necessidade de compreender a realidade daqueles que frequentam escolas públicas no país.

O tema contextualização vem sendo discutido por autores como Fernandes et al. (2011), Reis (2004) e Zabalza (2012), que balizam estudos desenvolvidos por estudantes, professores e pesquisadores em Universidades e estabelecimentos de educação. Tais pesquisas apontam inúmeras reflexões, dentre elas, sobre a necessidade de contextualizar o currículo nas escolas para que os alunos percebam a proximidade que existe entre eles e o conhecimento que lhes é mediado de maneira significativa.

[...] o contexto local deve ser entendido como o ponto de partida e de chegada para a construção de novas aprendizagens e novos conhecimentos significativos, onde a prática educativa atuaria como o fio condutor da comunicação entre os diversos saberes (locais, globais, culturais, científicos etc.). (REIS, 2004, p. 118).

Para o autor, a educação deve partir do campo, considerando-o também como ponto de partida e de chegada para alcançar um ensino de qualidade para educadores e educandos. Essa atuação deverá acontecer democraticamente, com a participação de todos que formam a escola e que possuem objetivos a serem alcançados para a melhoria da educação. Não podemos esquecer que o território camponês é constituído por sujeitos de direitos, que devem compreender seu espaço, atuando de maneira crítica e reflexiva para conquistar benefícios para tal realidade visando sempre ao bem social de todos aqueles que formam e mantêm viva aquela localidade.

Uma das funções dos currículos de educação do campo será a de dar centralidade política e pedagógica ao direito da infância e da adolescência, dos jovens e dos adultos do campo a se conhecerem nessa especificidade histórica e de garantir o seu direito a se reconhecerem nesses processos de segregação e inferiorização. A histórica inferiorização dos povos do campo se traduz nas representações sociais, políticas e culturais, que 
carregam essas marcas inferiorizantes dos coletivos diversos. Desconstruir essas representações será uma função da escola do campo. (ARROYO, 2012, p. 237).

A contextualização do currículo contribui para que as escolas tenham propostas educativas que possibilitem o conhecimento da história local encaminhando os educandos para o reconhecimento de seus direitos. A formação dos sujeitos será, assim, construída através de reflexões que partirão de sua realidade e da história do seu povo. "Ampliar o espectro social a fim de que se reconheçam os sujeitos do campo como sujeitos de direitos é passo importante para a conquista de políticas públicas" (MOLINA, 2012, p. 593). Por meio dessa contextualização, tanto educandos quanto todos os sujeitos envolvidos no processo de educação podem notar o quanto o conhecimento está próximo deles e assim buscar a valorização das identidades, conhecendo seus direitos e trabalhando para que estes sejam postos em prática, transformando, assim, sua realidade.

A cultura camponesa precisa ser valorizada, principalmente, nas escolas do campo, por seus sujeitos. O campo apresenta elementos naturais que podem ser utilizados na construção de saberes propostos pelas escolas, que podem partir do ambiente para realizar sua prática educativa. É importante salientar que a cultura camponesa neste trabalho é assim entendida:

[...] sujeito social histórico se forja em condições sociais, materiais e políticas acentuadamente adversas que marcarão suas culturalidades. [...] O mundo camponês é formado por ecossistemas complexos, dos quais é preciso recolher e/ou transformar os materiais da natureza para assegurar a satisfação das necessidades vitais e a reprodução social. (TARDIN, 2012, p. 181-182).

Percebe-se que a cultura camponesa é caracterizada por uma heterogeneidade de fatores e características, dentre elas o contato com a natureza na educação do campo. Defende-se que esse contato deve ser utilizado nas formas de ensinar para que as características da cultura deste espaço sejam enfatizadas na escola, permitindo que os educandos percebam o quanto o campo é rico em elementos que podem contribuir com a construção de saberes.

O objetivo deste texto foi analisar como o processo de contextualização do currículo contribui para a valorização da realidade campesina, verificando como os profissionais da educação percebem essa importância no processo de ensino-aprendizagem dos educandos como sujeitos de direito que estão em processo de formação. 


\section{Contextualização como elemento essencial na construção do currículo escolar}

As discussões a respeito da contextualização curricular são recentes no campo da educação. Pode-se notar a necessidade de incluir o contexto em que os educandos estão inseridos nas práticas pedagógicas, mas contextualização não se resume apenas ao contexto local dos educandos e sim a vários aspectos em que educando, comunidade escolar, corpo docente e escola estão envolvidos.

A contextualização curricular não está referida apenas a reduzir o conhecimento do educando à sua própria localidade, mas que este tenha a oportunidade de construir o conhecimento partindo das especificidades locais para o global; por isso, concorda-se com Reis (2004, p. 123) quando afirma que:

É preciso que o currículo se constitua num campo de insurgências e transgressões epistemológicas, possibilitando a comunicação dos saberes locais com os saberes globais como estratégia de ampliar a concepção de mundo desses sujeitos acerca do contexto em que vivem na tessitura do cotidiano, para que assim possam melhor conhecer o seu mundo a partir das suas próprias e de outras referências, outras realidades, criando novas maneiras e formas de atuar sobre ele.

É necessário o conhecimento de outras culturas, outras realidades, mas sobretudo é essencial que o educando conheça e valorize a sua própria cultura para que possa valorizar a sua realidade notando que o seu contexto faz parte de sua história, bem como de sua formação.

Percebe-se que o conhecimento do educando pode ser construído quando este conhece sua cultura, ao mesmo tempo em que respeita a cultura do outro. Esse aspecto da contextualização permite que a escola não construa ensinamentos preconceituosos a respeito de outras culturas que se distanciam das culturas dos sujeitos da escola.

É fundamental que o currículo trabalhe com habilidades que vão além do desenvolvimento cognitivo e envolvam diferentes campos da cultura, garantindo a presença de produções culturais dos mais diferentes grupos sociais e culturais, de tal modo que os estudantes sejam capazes de lidar com a diferença, valorizando e respeitando a cultura do outro, condição necessária para a vida em uma sociedade realmente democrática. (SANTOS, 2009, p. 13-14).

É importante que a escola defenda essa postura de construção de uma sociedade democrática. Esses posicionamentos são de grande relevância para 
que os sujeitos em formação sejam críticos, respeitando a sua e outras culturas por meio da formação em uma escola que enfatize essas ideias nas práticas mediadas pelo envolvimento com o currículo.

A contextualização não distancia os sujeitos de outras culturas, mas cabe ao educador desenvolver metodologias em que os educandos valorizem a sua realidade e respeitem as diversas realidades que existem além da sua. Nota-se a grande importância de se pensar o outro quando pensamos naqueles que denominamos como diferentes. É interessante se pensar isso com os educandos, para que não sejam construídas opiniões preconceituosas de quem pertence a outras culturas que se diferenciam das nossas.

Junto ao reconhecimento da própria identidade cultural, outro elemento a ser ressaltado relaciona-se às representações que construímos dos outros, daqueles que consideramos diferentes. As relações entre nós e os outros estão carregadas de dramaticidade e ambiguidade. (MOREIRA; CANDAU; 2007, p. 27).

Apresentam-se aqui dois autores: Fernandes et al. (2011) e Zabalza (2012), os quais apontam perspectivas de contextualização curricular que podem ser pensadas para atender às demandas das escolas que almejam alcançar seus objetivos através da contextualização, que enfatizam em suas propostas a cultura local da instituição escolar.

A respeito da contextualização, concorda-se com Fernandes et al. (2011, p. 06), que apresentam quatro perspectivas da contextualização curricular: "1a perspectiva: o local como referência; $2^{a}$ perspectiva: o sujeito/aluno como referência; $3^{\underline{a}}$ perspectiva: a prática pedagógica como referência; $4^{\underline{a}}$ perspectiva: a formação para a diversidade como referência".

De acordo com Fernandes et al. (2011), a contextualização pode acontecer tendo como referência quatro elementos diferentes que estão relacionados à escola e que ao mesmo tempo se relacionam entre si. Abordaremos aqui cada uma das concepções apresentadas pelo autor.

Zabalza (2012, p. 07) apresenta quatro relações entre contexto e elementos relacionados com a escola: "Analisa-se a contextualização curricular segundo quatro perspectivas: (1) o contexto como agente e construção da identidade dos escolares; (2) contexto e instituição escolar; (3) contexto e currículo; (4) contexto e metodologia didática".

Tendo o "local como referência",

Esta abordagem de contextualização curricular assenta no pressuposto de que o currículo deve ser adaptado de acordo com o contexto em que é leccionado, isto é, de acordo com as características do local: os traços culturais; os hábitos de vida, 
costumes e saberes do quotidiano do local. Deste modo se constrói um currículo próximo da realidade conhecida e vivida pelos alunos, onde os conteúdos escolares podem facilmente ser relacionáveis com as situações de vida real. (FERNANDES et al., 2011, p. 586).

Nesta perspectiva de contextualização curricular percebe-se que o currículo deve estar relacionado às características próprias do lugar em que a instituição se encontra, relacionando os costumes, hábitos, entre outras características relacionadas ao local. Nessa contextualização se enfatizam os saberes locais que se relacionam às famílias e às vidas dos sujeitos que formam a escola.

Sobre a mesma perspectiva de contextualização, Zabalza (2012, p. 11): "El niño, cada niño o niña, es un ser que vive en un marco determinado del que hereda condiciones y necesidades tanto biológicas como culturales". O autor defende que os educandos possuem características que herdam do ambiente em que nascem e crescem e por isso é importante que no planejamento escolar sejam enfatizadas as características do local que contribuem para a formação da identidade dos educandos.

Outra perspectiva de contextualização curricular apresentada por Fernandes et al. (2011) é a que o sujeito/educando se encontra como referência:

Esta perspectiva de contextualização curricular desenvolve-se a partir da ideia de que o desenvolvimento do currículo deve partir do sujeito, neste caso, do aluno. A ideia patente assenta na crença de que os conteúdos curriculares sejam efectivamente significativos para os alunos, devem adequar-se aos interesses dos mesmos, às suas intenções, às suas necessidades e aos seus hábitos, dificuldades e êxitos. (FERNANDES et al., 2011, p. 587).

Nota-se que os objetivos da escola estarão relacionados ao educando. Tais propostas contribuirão para o desenvolvimento do currículo ao mesmo tempo em que os educandos terão voz participando ativamente do processo de pensar a educação destinada aos mesmos.

Em contrapartida Zabalza (2012) crítica a posição de Fernandes et al. (2011) quando afirma que:

El centro es el niño, se dice, y es en función de lo que cada niño/a es, que debemos organizar nuestro trabajo. Planteamiento errado, en mi opinión, pues el niño (no como ser abstracto sino como sujeto real) no existe al margen del contexto en el que ha nacido y en el que vive. (ZABALZA, 2012, p. 11). 
De acordo com o autor, os educandos são influenciados pelo contexto do local e, por isso, o currículo deve ser contextualizado de acordo com o local e não apenas com características endógenas dos sujeitos envolvidos no processo de educação. A contextualização, nesse sentido, não pode acontecer considerando apenas o sujeito e sim o local. Na perspectiva de Fernandes, o sujeito pode ser referência no processo de educação e ser autor da construção do currículo escolar.

Outra perspectiva apresentada por Fernandes é a que a prática pedagógica é referência do currículo:

Entende-se nesta perspectiva que a contextualização deve assentar em práticas pedagógicas diferenciadoras que favoreçam a aprendizagem e fomentem dinâmicas de sala de aula que respondem às necessidades, interesses, expectativas, ritmos e estilos diferenciados dos alunos. Afirmase a necessidade de uma educação significativa que ocorre por meio da contextualização do saber levada a cabo pelo trabalho pedagógico dos professores. (FERNANDES et al., 2011, p. 588).

Desta forma a contextualização acontece nas práticas pedagógicas realizadas em sala de aula, que deverão se diferenciar sempre que necessário atendendo assim às demandas da escola e contribuindo para a contextualização do currículo. Com a contextualização das práticas pedagógicas desenvolvidas em sala de aula, consegue-se melhorar o processo de ensino-aprendizagem nas aulas.

A respeito das práticas pedagógicas Zabalza (2012, p. 22) afirma que:

Si descendemos al último de los anillos, el de la práctica educativa en las aulas (o fuera de ellas), la contextualización curricular sigue siendo toda una fuente de innovaciones e ideas para llevar a cabo una enseñanza más rica en estímulos y más cargada de significados para los estudiantes.

Pode-se afirmar, assim, que o currículo contextualizado irá contribuir para que os educandos aprendam na e para a vida, tornando-se críticos com uma metodologia caracterizada para atender aos anseios da escola. $O$ currículo contextualizado deverá propor inovações que sejam para que os educandos considerem o conhecimento significativo.

A quarta perspectiva de contextualização curricular apresentada por Fernandes et al. (2011) possui a formação para diversidade como referência:

O recurso à contextualização curricular como meio para responder à diversidade, seja esta definida pela existência de educandos em risco, pela crescente diversidade cultural e/ou, 
ainda, pela escolarização de povos indígenas de determinadas regiões e países. (FERNANDES et al., 2011, p. 589).

Percebemos que o autor aponta que é preciso estar atento para atender à diversidade que se encontra nas escolas.

Além dos aspectos de contextualização já apresentados, Zabalza (2012, p. 15) cita ainda sobre o contexto e a instituição escolar que:

La forma como las escuelas se relacionan con el contexto tiene mucho que ver con la concepción que se tenga de la escuela y de la función que ésta debe desarrollar como instancia social. Ésa es la gran pregunta que las instituciones escolares deben plantearse y replantearse en cada nuevo periodo: ¿cuál es la función de la escuela em este momento?, ¿qué espera la sociedad de ella?

Nesse aspecto da instituição, nota-se a importância de se enfatizar a função da escola que deve ser pensada de acordo com o que a sociedade espera dessa instituição de ensino. Isso implica em considerar a escola como referência no processo de contextualização curricular. Pretende-se nesta abordagem pensar qual a função da escola e o que a sociedade espera da instituição.

O mesmo autor aponta a perspectiva de contexto e currículo escolar levando em consideração que se pense o currículo com o projeto formativo da escola em que o território deve possuir grande importância no cotidiano da escola. Sendo assim o projeto formativo deve ser baseado não em regulamentos oferecidos pelo sistema e sim pela situação atual que o entorno da instituição oferece, conforme aponta Zabalza (2012).

Nota-se que ambos os autores apresentam perspectivas sobre contextualização curricular, que contribuem para que as escolas possam atender às demandas dos educandos, a escola e todos os que compõem a instituição. Por meio da contextualização curricular é possível alcançar os resultados esperados pela escola.

Vê-se que através de um ensino contextualizado é possível formar sujeitos que sejam capazes de atuar na sociedade solucionando seus problemas, podendo, assim, melhorar a qualidade de vida do meio em que estão inseridos. Para isso é preciso que a escola se aproxime cada vez mais da comunidade e de suas características, utilizando dados para construir o conhecimento. Percebe-se que a contextualização não se resume apenas ao local e sim a vários aspectos como os estudiosos da contextualização curricular defendem.

A educação contextualizada requer modificações que devem ser pensadas com o objetivo de atender aos desejos do próprio contexto. Dessa 
forma se percebe que a educação deve ser na vida e para a vida dos sujeitos envolvidos nesse processo.

Neste trabalho foram apresentadas perspectivas de contextualização diferentes dos autores Fernandes e Zabalza. Levando em consideração a notável divergência entre as definições, optou-se pela utilização de Fernandes para a realização de inferências na análise dos dados coletados, embasandose na ideia de que o educando deve ser o foco das práticas educativas a serem desenvolvidas em sala de aula.

Na educação do campo é importante dar ênfase ao educando, pois se entende que o campo oferece aos seus sujeitos a própria organização para a produção de vida. "O campo, nesse sentido, mais do que um perímetro não urbano, é um campo de possibilidades que dinamizam a ligação dos seres humanos com a própria produção das condições da existência social e com as realizações da sociedade humana" (BRASIL, 2008, p. 01). Através do Parecer das Diretrizes Operacionais para a Educação Básica nas Escolas do Campo, compreende-se a importância dos sujeitos do campo, que devem conhecer suas diretrizes para reivindicar o direito a uma educação que enfatize as particularidades e especificidades do campo.

O que se almeja é que os sujeitos do campo tenham a seu favor uma escola destinada aos mesmos, que não seja uma educação copiada da cidade, mas que a escola esteja no e seja para o campo, o que se pretende por meio da educação do/no campo. "Trata-se, portanto, de uma concepção que emerge das contradições da luta social e das práticas de educação dos trabalhadores do e no campo" (MOLINA; SÁ, 2012, p. 326). Nota-se que é direito dos sujeitos do campo uma educação em todas as modalidades destinadas a estes sujeitos e que tal educação seja de qualidade.

\section{Percurso metodológico da pesquisa}

A abordagem metodológica utilizada na construção deste trabalho foi qualitativa do tipo estudo de caso, em que se pretende analisar os fatos sociais de um caso. "Na abordagem qualitativa não existirá neutralidade do pesquisador em relação à pesquisa, pois ele atribui significados, seleciona o que do mundo quer conhecer, interage com o conhecido e se dispõe a comunicá-lo" (NOVENA, 2008, p. 148).

Neste trabalho se enfatiza a contextualização na educação do campo tendo em vista que a escola pesquisada participa de formações que têm como objetivo a contextualização curricular, ou seja, parte da realidade campesina para ensinar. 
Os dados foram coletados por meio de uma entrevista semiestruturada que, segundo Martins (2008, p. 27), o seu "objetivo básico é entender e compreender o significado que os entrevistados atribuem a questões e situações, em contextos que não foram estruturados anteriormente, com base nas suposições e conjecturas do pesquisador". A entrevista foi gravada através de gravador de aparelho celular, seguindo um roteiro com 16 pontos relevantes para a pesquisa.

O local da pesquisa foi uma instituição municipal localizada na zona rural da cidade de Bananeiras/PB. Os sujeitos da pesquisa (Quadro 01) foram professores, gestores atuais e antigos, gestores que participaram das formações que foram realizadas na escola enquanto estavam sendo realizadas reuniões para a construção do Projeto Pedagógico Curricular (PPC) contextualizado, tendo-se em vista a importância da participação de todos os sujeitos que formam o corpo docente da escola para a construção do Projeto contextualizado de acordo com a realidade campesina. Vale salientar que antigos gestores foram entrevistados porque participaram do processo de construção inicial do PPC da escola do campo pesquisada.

\section{Quadro 01: Sujeitos da pesquisa}

\begin{tabular}{|l|l|l|}
\hline \multicolumn{3}{|c|}{ CARACTERIZAÇÃO DOS SUJEITOS DA PESQUISA } \\
\hline $\begin{array}{l}\text { Atuação em 2015, } \\
\text { participantes das formações } \\
\text { realizadas na escola. }\end{array}$ & $\begin{array}{l}\text { Atuação em anos antecedentes a } \\
\text { 2015, participantes das reuniões, } \\
\text { mas que atualmente estão } \\
\text { trabalhando em outras escolas. }\end{array}$ & $\begin{array}{l}\text { Aposentada que estava em } \\
\text { exercício nos anos } \\
\text { antecedentes a 2015 e que } \\
\text { participou das reuniões. }\end{array}$ \\
\hline 07 & \multicolumn{1}{|c|}{01} & \multicolumn{1}{c|}{01} \\
\hline
\end{tabular}

Fonte: Autoras.

Os dados foram coletados e analisados por meio de categorias. Neste trabalho é apresentada a categoria contextualização cujo indicador foi apresentar a forma como os professores veem a importância de contextualizar o ensino para que os educandos percebam o significado do ensino para eles, notando a aproximação dos conteúdos com a realidade do campo.

A análise dos achados da pesquisa foi realizada a partir da análise de conteúdo de Bardin (2011), em que se desmembrou o texto em categorias para melhor realizar o estudo da pesquisa, considerando as opiniões dos sujeitos entrevistados que puderam expressar suas ideias a respeito do que consideram relevante sobre a contextualização curricular.

\section{Analisando os dados da categoria contextualização}

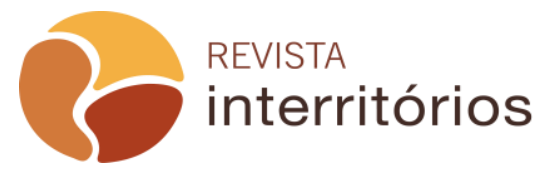


A categoria contextualização é caracterizada pela relação que as educadoras devem fazer dos conteúdos ensinados com a realidade dos educandos e das especificidades que o campo em que a escola está inserida possui. Compreende-se que para fazer essa relação necessária para a contextualização é preciso que os educadores estejam aptos a mudarem sua prática pedagógica sempre que possível, para que a educação na escola seja contextualizada de acordo com a realidade campesina.

Concorda-se com Fernandes et al. (2011, p. 584):

Os sentidos expressos sobre contextualização curricular conferem-lhe um estatuto central nos processos de ensino e de aprendizagem, porquanto permitem uma aproximação destes processos às vivências reais dos alunos contribuindo, deste modo, para que as aprendizagens sejam mais significativas e, por isso, os alunos ampliem os conhecimentos. Em síntese, fica evidente o recurso à contextualização do currículo como condição que favorece o sucesso educativo dos alunos.

Nota-se aí a importância da contextualização para a ampliação da construção do conhecimento dos educandos. Aproximar os conteúdos a serem trabalhados da realidade em que os educandos estão inseridos é importante para que os mesmos percebam a relação de suas vidas e vivências com o aprendizado adquirido na escola.

O quadro 02 apresenta narrativas que expressam algumas das perspectivas de contextualização discutidas no texto. Fernandes et al. (2011) apresentam tais perspectivas considerando-as como relevantes para alcançar objetivos significativos na educação, levando em consideração a realidade dos educandos. Tais perspectivas são: contexto, construção e identidade; contexto e instituição escolar; contexto e currículo; contexto e metodologia didática.

Quadro 02: Categorias analisadas com as narrativas das professoras

\begin{tabular}{|c|c|c|}
\hline CATEGORIA & PERSPECTIVA & EXCERTOS DAS NARRATIVAS \\
\hline & $\begin{array}{c}\text { Contexto e construção } \\
\text { da identidade }\end{array}$ & $\begin{array}{l}\text { Ano passado na segunda-feira eu gostava de } \\
\text { fazer com eles (os alunos) roda de conversa e } \\
\text { era interessante, porque saía cada história } \\
\text { que eles contavam que foram ao terço, } \\
\text { quando iam pra celebração. [...] Eles contam } \\
\text { cada história que nem você sabe. A gente } \\
\text { aprende com as histórias dos alunos (Gestora } \\
\text { da escola, 2015). }\end{array}$ \\
\hline & $\begin{array}{c}\text { Contexto e instituição } \\
\text { escolar }\end{array}$ & $\begin{array}{l}\text { Eu tento trazer materiais que envolvam eles } \\
\text { para que eles percebam essa realidade, para } \\
\text { que essa realidade não se distancie do que } \\
\text { eles conhecem (Educadora "C", 2015). }\end{array}$ \\
\hline & Contexto e currículo & Deu para contribuir um pouco, né, porque a \\
\hline
\end{tabular}




\begin{tabular}{|l|l|l|}
\hline CONTEXTUALIZAÇÃO & $\begin{array}{l}\text { gente dá a atividade da gente de acordo com } \\
\text { a região da gente porque eles já sabem, já } \\
\text { conhecem, eles também já trabalham junto } \\
\text { com o pai e eles já sabem o que é que } \\
\text { colhemos aqui (Educadora "A", 2015). }\end{array}$ \\
\cline { 2 - 3 } & $\begin{array}{l}\text { Contribuíram e muito porque a partir das } \\
\text { metodologia didática } \\
\text { formações você começa a dar sentido a tudo o } \\
\text { que você leva em sala de aula, começa a } \\
\text { fazer com que os alunos compreendam, os } \\
\text { alunos já começam a compreender por si sós } \\
\text { quando você começa a levar de uma maneira } \\
\text { diferente, quando você procura adaptar aquele } \\
\text { conteúdo, você vai falar de campo, não vai } \\
\text { falar de campo como se fosse uma coisa } \\
\text { distante [...] (Educadora "D", 2015). }\end{array}$ \\
\hline
\end{tabular}

Fonte: Autoras.

De acordo com as narrativas das educadoras, percebe-se que elas tentam aproximar o campo das aulas realizadas em sala, mas ainda há muito a se fazer para alcançar objetivos significativos que possam ser definidos como contextualização. Compreende-se, portanto, que envolver o contexto nas aulas é um trabalho que deve ser constante e que deverá estar sempre se transformando, uma vez que se percebe que os sujeitos estão em constante mudança.

Para entender contextualização neste trabalho, foi questionado como os sujeitos da pesquisa se atualizam para atender às necessidades dos educandos, ao mesmo tempo em que se planejam as aulas levando-se em consideração que todos os sujeitos (educandos) são do campo.

A educadora "A" respondeu: "Coisas mais para melhorar os alunos, que venham mais coisas, mais para melhorar o ensinamento deles pra eles terem mais rendimento" (Educadora "A").

Nessas falas, percebe-se que a gestora, quando ainda era educadora, preocupava-se em atuar de maneira que procurasse saber algo sobre a vida extraescolar dos educandos. Isso é interessante desde que se relacione com as atividades e práticas em sala de aula. Estabelecer relações com os educandos é importante para que as práticas de contextualização sejam significativas na escola.

As narrativas acima não apresentam informações a respeito de como se realiza o planejamento das aulas, mas informam o que a gestora " $A$ " considera em relação à realidade dos educandos, enquanto que a educadora " $A$ " almeja inovações para melhorar o ensinamento.

Concorda-se com a afirmação que "será esta relação entre o saber oficial e o saber provindo das situações quotidianas que permitirá aos alunos avançar no aprofundamento do conhecimento, um conhecimento que se 
pretende que seja útil e projectável no futuro" (FERNANDES et al., 2011, p. 587). Percebe-se que deve haver uma relação entre o saber da escola e o saber adquirido com as vivências dos educandos para que se trabalhe nas escolas uma aprendizagem significativa.

Para a educadora $\mathrm{C}$ é importante no momento de planejamento estar atenta ao que os educandos da escola conhecem: "Eu tento trazer materiais que envolvam eles para que eles percebam essa realidade, para que essa realidade não se distancie do que eles conhecem" (Educadora "C").

Nota-se aqui que as entrevistadas tentam relacionar pesquisas e o uso de novos materiais com as atividades a serem desenvolvidas com os educandos. Um dos pontos apontados pelas educadoras é que os educandos têm dificuldade em ler e escrever, isso provoca constrangimento em contextualizar o ensino, pois é uma tarefa difícil que acontece em um processo lento e é necessário que os educadores entendam o ritmo de aprendizagem dos educandos, por isso é importante partir dos mesmos para ensinar.

A contextualização pode acontecer na medida em que se ensina a ler e a escrever, o processo de contextualização se realiza no mesmo momento do ensinamento, as dificuldades de aprendizagens dos educandos poderão ser trabalhadas ao mesmo tempo em que as práticas de contextualização acontecem, pois, a contextualização deve ser uma proposta curricular a ser posta em prática em todas as séries que a escola atende.

Concorda-se com Fernandes et al. (2011, p. 588) quando afirmam:

A contextualização deve assentar em práticas pedagógicas diferenciadoras que favoreçam a aprendizagem e fomentem dinâmicas de sala de aula que respondem às necessidades, interesses, expectativas, ritmos e estilos diferenciados dos alunos. Afirma-se a necessidade de uma educação significativa que ocorre por meio da contextualização do saber levada a cabo pelo trabalho pedagógico dos professores.

A contextualização deve acontecer de maneira a melhorar a aprendizagem dos educandos contribuindo para que os educadores possam partir, além das vivências pessoais e dos acontecimentos do contexto dos mesmos, das dificuldades e particularidades desses sujeitos, para que o ensino seja contextualizado de maneira positiva para a escola e os sujeitos que a formam.

Os educadores que se empenharem em contextualizar o ensino devem partir de todas as características que são e que envolvem os educandos no processo de ensino. É importante que a contextualização do saber proporcione uma educação significativa que aconteça com os educandos de forma que estes possam se perceber como participantes do processo de ensino. 
Para planejar é importante que as educadoras escutem os educandos, é interessante enfatizar no planejamento o que os alunos desejam para a sua própria educação. A contextualização propõe que os desejos dos alunos sejam atendidos no processo de ensino e aprendizagem, uma vez que se entende que a educação será destinada a eles tendo os professores como mediadores do processo.

Um recurso importante que os entrevistados apontaram para a contextualização foram os livros da "Coleção Girassol" que eram destinados às escolas do campo. Nota-se isso na afirmação:

O livro Girassol, ele já vem bem... eu gostei desse livro, ele vem já... ele atende mesmo as necessidades, mas quando algo... porque eu gostei realmente dele, mas, eu não fico só nele, eu procuro outras fontes também. Mas eu gostei dele, ele já traz um "resumão" bem... se você, você pega quando o assunto de medidas é bem pra essa realidade mesmo. Eu gostei demais, quando eu vi eu só pesquisei outras metodologias de passar o conteúdo porque também tem que adaptar aos recursos que a escola possui (Educadora “D”).

Nota-se aqui que os livros da Coleção Girassol podem ser utilizados de forma a contribuir também com a contextualização do ensino. É importante perceber que não é suficiente apenas a utilização do livro, mas, como é posto na narrativa da entrevistada, o livro é um bom recurso que pode contribuir com pesquisas de metodologias que proporcionem também a contextualização.

É importante que os educadores pesquisem materiais que auxiliem na contextualização. Ensinar com livros referentes ao campo é interessante para que os educandos percebam a aproximação entre o contexto em que estão inseridos e os assuntos que estudam na escola e que fazem parte da sua formação.

A utilização de materiais didáticos para as aulas deve estar adequada às vivências dos educandos, assim será também uma forma de contextualizar, se os educadores utilizarem tais materiais para esse fim. O livro didático não pode ser o único material didático a ser utilizado pelos professores, é necessária a utilização de outros materiais que a escola possui, bem como utilizar materiais encontrados no próprio campo.

Pode-se afirmar que para que se desenvolva a contextualização em sala de aula não existe uma fórmula pronta, não existe uma forma de ensinar que fará todos os educandos aprenderem de uma só vez, é necessário que os educadores se empenhem em adequar o que será ensinado com a vida dos educandos, para que aconteça uma aproximação entre o ensinar e o aprender causada pela contextualização. 
A utilização de materiais pode facilitar a forma de ensinar, mas os educadores não podem depender apenas dos materiais didáticos que a escola disponibiliza, pois, é necessário que os pontos de partida e de chegada para ensinar sejam os educandos. Percebe-se isto quando a educadora "E" afirma:

Em geografia, história a gente faz. Inclusive até o assunto de
história é sobre a comunidade. A gente trabalha com o livro
Girassol, geografia também é de acordo com a paisagem,
porque o da escola do campo era pra ser aquele livro; aí a
gente quando foi na escolha do livro a gente escolheu Girassol,
aí como não deu e o que sobrou pra nossa escola aí foi: "Porta
Papel é Prosa", foi uma misturada medonha; a gente não tinha
todos os livros. Quando foi esse ano sobraram muitos livros, aí
eu falei com a menina na Secretaria, com a coordenadora e
disse: mulher, eu queria uns livros pra os meus alunos, aí eu
consegui a quantidade de livros dos meus alunos aí, "A", disse
"B" eu vou ver se eu também consigo pra os meus alunos; aí a
gente conseguiu a quantidade de livros pra o $3^{\circ}$ e o $4^{\circ}$ ano,
todos os meus alunos têm livros e os de "A" a gente tá
trabalhando com ele aí eu achei bom porque ele é a realidade.
Lá quando "C" trabalhava era Porta Aberta, era Prosa, era uma
mistura medonha, eu digo eu não quero esse livro não
(Educadora "E").

Compreende-se que o livro da Coleção Girassol é um recurso significativo para as aulas nas escolas do campo. No entanto, não pode ser o norte para as aulas, pois existe uma realidade no contexto da escola que não é conhecida pelos autores do livro. Os elementos da realidade são conhecidos pelos educandos e provavelmente pelos educadores e é essa realidade que deve ser enfatizada no planejamento das aulas.

[...] percebemos que os livros da coleção Girassol: saberes e fazeres do campo, tanto nas ilustrações apresentadas quanto nas atividades propostas, estão correlacionados à vida dos "Campos", possibilitando ao professor oportunidades para o desenvolvimento das atividades calcadas na Educação do Campo, de forma a trabalhar conteúdos fundamentados no rural e nos seus diversos aspectos, o que pode fortalecer um processo de construção de uma identidade do sujeito e da escola do campo. Desta forma, concluímos que a proposta oportuniza contextualizar, visando atender ao sujeito do campo, abrangendo sua cultura e outras características que lhes são peculiares. (AZEVEDO et al., 2013, p. 14).

Nota-se o quanto os livros da Coleção Girassol podem contribuir para a contextualização do ensino nas escolas do campo, sendo necessário que os educadores relacionem os conteúdos dos livros didáticos com a realidade do campo em que a escola está inserida. Análises realizadas sobre a Coleção Girassol apontam que as formas como se trabalham os conteúdos nos livros da

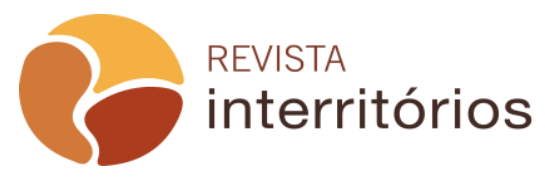

Interritórios | Revista de Educação

Universidade Federal de Pernambuco, Caruaru, BRASIL | V.5 N.9 [2019] 
coleção contribuem para a valorização da identidade campesina, ajudando os sujeitos a compreenderem as especificidades que estão presentes no campo.

O educador deve procurar recursos que facilitem a contextualização de forma que possibilitem uma aprendizagem próxima ao conhecimento que os educandos possuem, advindos de sua vivência, no contexto social em que vivem. Assim, compreende-se que os conhecimentos locais se aproximam dos saberes científicos favorecendo uma aprendizagem em que o educando perceba o significado do que estará aprendendo.

Um ponto importante para a contextualização, segundo as entrevistadas, é o diálogo que deve acontecer em sala de aula para que se conheça cada vez mais a realidade dos educandos. Percebe-se isso quando a gestora da escola afirma que a formação realizada pelo projeto de extensão

Contribuiu, é pra eles um diálogo porque sempre tem alunos que são mais tímidos e eu gosto de fazer com os meus alunos roda de conversa como a Formadora de Arte fazia. Sempre dar espaço para o aluno falar, eu sempre fazia isso nos finais de semana com os meus alunos, às vezes, o professor não dá voz ao aluno, é bom, o professor tem que sempre ir conversando pra ele poder se expressar melhor (Gestora da escola, 2015).

É importante dar voz e vez ao educando para que ele se sinta participante da construção dos seus conhecimentos. A contextualização acontece para que o conhecimento seja construído com os educandos e não passados para eles como algo pronto e acabado. Os educadores podem estar constantemente se adequando às necessidades dos educandos, procurando partir dos saberes locais para atender às demandas cabíveis.

Concorda-se com Leite e Fernandes (2002 apud FERNANDES et al., 2011, p. 587), "um pouco na lógica de "dar voz aos alunos" e proporcionar-lhes um papel activo quer nos processos de definição dos conteúdos e do desenvolvimento, quer na regulação nos processos de formação". Entende-se que a contextualização quando tem como foco principal o educando, deve escutar esse sujeito para inserir sua participação ativa no processo de educação.

É importante ressaltar a importância dada à região também quando se enfatiza a fala da entrevistada: "Eu tento trazer materiais que envolvam eles para que eles percebam essa realidade, para que essa realidade não se distancie do que eles conhecem" (Educadora "C"). Nota-se aqui que o foco principal das entrevistadas é o contexto da escola. Principalmente o trabalho com a terra que deve ser enfatizado nas aulas, uma vez que faz parte da vida e da formação dos educandos. Dar ênfase à realidade do trabalho dos pais na escola é uma forma de valorizar a identidade do campo ao mesmo tempo em 
que se contextualiza o ensino não o distanciando do trabalho realizado no campo.

Realizar uma aproximação entre os acontecimentos do contexto e o conteúdo ensinado nas escolas do campo é importante no processo de contextualização. "Será esta relação entre o saber oficial e o saber provindo das situações quotidianas que permitirá aos alunos avançar no aprofundamento do conhecimento, um conhecimento que se pretende que seja útil e projectável no futuro (FERNANDES et al., 2011, p. 587). A contextualização proporciona um ensinamento em que os educandos possam ser formados para atuarem em uma sociedade de forma crítica. A necessidade de relacionar o saber oficial com o saber do contexto proporciona um melhor ensinamento em que os educandos possam perceber essa aproximação.

Pode-se afirmar que a contextualização facilita a aprendizagem nas escolas do campo quando analisamos a afirmação da educadora "D":

Contribuíram e muito porque a partir das formações você começa a dar sentido a tudo o que você leva em sala de aula, começa a fazer com que os alunos compreendam, os alunos já começam a compreender por si só mesmo quando você começa a levar de uma maneira diferente, quando você procura adaptar aquele conteúdo, você vai falar de campo, não vai falar de campo como se fosse uma coisa distante, e em casa como é que é? O seu pai o que produz? Você já contextualiza com o que eles têm em casa e pra isso você começa numa conversa: o que é que você tem em casa? $O$ que é que fazem? O que é que o seu pai faz? Aqui tem uma problemática: uns têm pai, outros são criados com avó, aí mistura tudo, e aí é muito heterogênea, aí você diz assim... não cortando o teu raciocínio é muito difícil ensinar em sala multisseriada, mas quando você vai olhar, na realidade todas são porque os níveis de aprendizagem dos alunos são diferentes, né? (Educadora "D").

Percebe-se na fala da entrevistada que a educação contextualizada nas escolas do campo, além de aproximar o conhecimento da realidade dos educandos, ainda contribui para que os mesmos valorizem o que faz parte do seu contexto e da sua formação. Envolver o trabalho dos pais e sua realidade nas aulas é uma forma de contextualizar em que o próprio educando vai partir da sua vida para construir o seu conhecimento.

Outro ponto importante a ser destacado pela entrevistada é a heterogeneidade que existe nas salas de aula na educação do campo, mesmo uma turma não sendo multisseriada, a heterogeneidade ainda existe. Mas isso não se torna um empecilho para que a contextualização aconteça, pois é possível contextualizar levando-se em consideração o contexto e os níveis de aprendizagem da turma. 
[...] a Educação Contextualizada nas escolas do Campo não pode ser entendida como o espaço do aprisionamento do conhecimento e do saber, ou ainda na perspectiva de uma educação localista, mas como aquela que se constrói no entrecruzamento cultura-escola-sociedade-mundo. (REIS, 2004, p. 127).

Concorda-se com o autor quando afirma que deve acontecer uma relação entre todos os elementos que fazem parte da formação do sujeito na sociedade. A educação contextualizada nas escolas do campo não pode acontecer de forma localista, mas de maneira a relacionar elementos inter e extraescolares.

É importante que as educadoras do campo percebam as particularidades existentes no campo para ensinar, pois é possível encontrar elementos essenciais para ensinar no próprio contexto em que a escola está inserida. Percebe-se isso na fala das entrevistadas que afirmam:

Contribuiu bastante, também a gente teve mais noção do espaço, a gente não tinha essa noção do espaço, né, que ele orientou a gente a respeito do espaço porque a gente não tinha essa noção porque nós não víamos da maneira que ele explicou (Educadora "B").

Sim, tanto pra um como para outro, de modo geral, né, a gente não vai falar daqueles que têm aquela dificuldade porque [...], mas serviu na aprendizagem tanto pra mim como pra eles. Através assim de a gente pronto de aula de campo né, de a gente passar assim vídeos (Educadora "E").

Nessa fala se percebe que, através das formações que foram realizadas na escola durante os anos de 2013 e 2014, de que educadoras das escolas do campo participaram, foi possível que as mesmas notassem o quanto o espaço em que a instituição está inserida é rico em aspectos geográficos que podem ser utilizados nas aulas do componente curricular geografia ministrado na escola. Mas, também é necessário notar que é preciso dar uma atenção específica para os educandos com dificuldade de aprendizagem, pois na contextualização é preciso levar em consideração a aprendizagem dos educandos.

O currículo deve estar organizado de maneira a atender às necessidades dos educandos. "Esta constatação corrobora a ideia de que o recurso à contextualização curricular está diretamente relacionado com as possibilidades pedagógicas oferecidas pelos professores no contexto de sala de aula" (FERNANDES; FIGUEIREDO, 2012, p. 170). Concorda-se com essa afirmação, pois a contextualização deve partir dos educandos; sendo assim, é preciso enfatizar as necessidades dos educandos para que esse recurso seja 
significativo para esses sujeitos que devem fazer parte do processo de educação.

Nessa categoria foram destacadas as contribuições que as formações realizadas na escola do campo causaram no processo de (re) significação do currículo, as mudanças e dificuldades realizadas e encontradas no processo. A contextualização não acontecerá em um passe de mágica, do dia para a noite. As educadoras passarão por um momento de transformações da sua prática pedagógica se desejarem alcançar o objetivo de contextualizar para valorizar a realidade do campo.

\section{Considerações finais}

A partir da análise da categoria contextualização é possível perceber que as educadoras estão em processo de mudança na forma de ensinar. Notase que estas esperam mais das formações que acontecem na escola, mas é importante que as mesmas se esforcem para se atualizarem constantemente.

Para que o processo de contextualização contribua para a valorização da realidade campesina se faz necessário que as educadoras estejam empenhadas nesse trabalho de associar as aulas e suas práticas pedagógicas à realidade dos educandos. Por isso, compreende-se que a contextualização acontece em sala de aula por meio de uma iniciativa dos docentes. É necessário que o ensinar e o aprender estejam constantemente sendo construídos, para que todos que fazem parte do processo percebam 0 significado da aprendizagem.

Contextualizar o ensino não é uma tarefa fácil para educadores, mas é algo possível se os mesmos se empenharem e considerarem a contextualização como objetivo de suas aulas. Dessa forma será possível que tanto educadoras quanto educandos aprendam constantemente com as aulas, retirando do próprio campo conhecimentos significativos para ambos.

A participação nas formações realizadas para a escrita do PPC da escola contribui para que as educadoras compreendam a importância da contextualização, o quanto é necessário partir do contexto para ensinar e dessa forma tornar o ensino significativo. As narrativas mostraram que ainda há muito a se fazer no e pelo campo. É preciso que as educadoras percebam a realidade como sendo o norte para planejar suas aulas e para construir conhecimento com os educandos. 


\section{REFERÊNCIAS}

ARROYO, Miguel G. Outros Sujeitos, Outras Pedagogias. Petrópolis, RJ: Vozes, 2012.

AZEVEDO, Ana Viviane Miguel de et al. Coleção girassol: subsídios para a formação do sujeito do campo? In: I Seminário Internacional de Educação do Campo da UFRB, II Seminário Estadual de Educação do Campo da Bahia, III Seminário de Educação do Campo do Recôncavo e Vale do Jequiriçá e IV Encontro de Educação do Campo de Amargosa. Anais "Educação e Desenvolvimento do Campo Brasileiro", Amargosa-BA: Gráfica Exemplar, 04 set. 2013.

BARDIN, Laurence. Análise de Conteúdo. Tradução: Luís Antero Reto, Augusto Pinheiro. São Paulo: Edições 70, 2011.

BRASIL. Parecer para Diretrizes Operacionais para a Educação Básica nas Escolas do Campo. Parecer: 36/2001. Brasília: Ministério da Educação/Conselho Nacional de Educação/Câmara de Educação Básica, 2008.

FERNANDES, P. et al. Sentidos atribuídos ao conceito de "contextualização curricular". In: LOZANO, A. et al. Libro de actas do XI congreso internacional galegoportugués de psicopedagoxía. Coruña: Editora da Universidade de Coruña, 2011. p. 581-592.

FERNANDES, Preciosa; FIGUEIREDO, Carla. Contextualização Curricular Subsídios para novas significações. Revista Interacções, n. 22, p. 163-177, 2012. Disponível em: http://www.eses.pt/interaccoes. Acesso em: 28 mar. 2015.

MARTINS, Gilberto de Andrade. Estudo de Caso: uma estratégia de pesquisa. 2. ed. São Paulo: Atlas, 2008.

MOLINA, Mônica Castagna. Políticas públicas. In: CALDART, Roseli Salete et al. Dicionário da Educação do Campo. Rio de Janeiro, São Paulo: Escola Politécnica de Saúde Joaquim Venâncio, Expressão Popular, 2012.

MOLINA, Mônica Castagna; SÁ, Lais Moura. Escola do Campo. In: CALDART, Roseli Salete et al. Dicionário da Educação do Campo. Rio de Janeiro, São Paulo: Escola Politécnica de Saúde Joaquim Venâncio, Expressão Popular, 2012.

MOREIRA, Antônio Flávio Barbosa; CANDAU, Vera Maria. Currículo, Conhecimento e Cultura: Currículo, Cultura e Sociedade. In: SALTO PARA O FUTURO, Indagações Sobre o Currículo do Ensino Fundamental, Brasília: Ministério da Educação, Secretaria de Educação a distância, boletim 17, set. 2007.

NOVENA, Nadia Patrizia. Pesquisando as narrativas da sexualidade na organização escolar: formulação do problema e adequação dos procedimentos metodológicos na pesquisa qualitativa. In: WEBER, Silke; FARIAS, Maria da Salete Barboza de. Pesquisas qualitativas nas ciências sociais e na educação: propostas de análise do discurso. João Pessoa: Editora Universitária da UFPB, 2008.

REIS, Edmerson dos Santos. A contextualização dos conhecimentos e saberes escolares nos processos de reorientação curricular das escolas do campo. 2004,

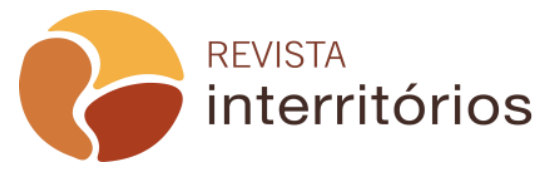


318 p. Tese (Doutorado) Universidade Federal da Bahia - Faculdade de Educação, Salvador. 2004.

SANTOS, Lucíola. A Construção do Currículo: Seleção do Conhecimento Escolar. In: SALTO PARA O FUTURO, Currículo: Conhecimento e Cultura, Brasília: Ministério da Educação, Secretaria de Educação a distância, ano XIX, n. 1, abr. 2009.

TARDIN, José Maria. Cultura Camponesa. In: CALDART, Roseli Salete et al.

Dicionário da Educação do Campo. Rio de Janeiro, São Paulo: Escola Politécnica de Saúde Joaquim Venâncio, Expressão Popular, 2012.

ZABALZA, M. B. Territorio, Cultura y Contextualización Curricular. Revista Interacções, n. 22, p. 6-33, 2012. Disponível em: http://www.eses.pt/interaccoes. Acesso em: 07 abr. 2015. 